\title{
ANALISIS PENGARUH PROMOSI DIGITAL TERHADAP PERILAKU \\ KONSUMTIF MAHASISWA PERBANKAN SYARIAH DALAM BERBELANJA ONLINE DENGAN RELIGIUSITAS SEBAGAI VARIABEL MODERASI
}

\author{
Alfiatus Nur Fadillah \\ syahalfiya@gmail.com \\ Darna \\ darna.saenan@gmail.com \\ Achmad Bakhrul Muchtasib \\ bakhrul.muchtasib@akuntansi.pnj.ac.id
}

Program Studi Keuangan dan Perbankan Syariah Politeknik Negeri Jakarta

\begin{abstract}
This study aims to determine the effect of digital promotion on consumer behavior of Islamic Banking students in shopping online, as well as to determine the effect of religiosity on the relationship between the two variables. The research method used is quantitative associative type. Respondents involved in this study were 279 Islamic Banking students from PNJ, STEI SEBI, and UIN Jakarta. Data collected through the distribution of questionnaires digitally. The collected data is then analyzed using a moderation type of path analysis. The results of this study indicate that digital promotion influences the consumptive behavior of Islamic Banking students in shopping online by $20.5 \%$. In addition, religiosity is able to decrease the relationship between digital promotion and consumptive behavior of Islamic Banking students in shopping online by $16.2 \%$. This research is expected to be useful for Muslim consumers to control their consumptive behavior by increasing their religiosity.
\end{abstract}

Keywords: Digital Promotion, Religiosity, Consumptive Behavior.

\begin{abstract}
ABSTRAK
Penelitian ini bertujuan mengetahui pengaruh promosi digital terhadap perilaku konsumtifmahasiswa Perbankan Syariah dalam berbelanja online, sekaligus untuk mengetahui pengaruh religiusitas terhadap hubungan antara kedua variabel tersebut. Metode penelitian yang digunakan adalah kuantitatif berjenis asosiatif. Responden yang terlibat dalam penelitian ini sebanyak 279 mahasiswa Perbankan Syariah dari kampus PNJ, STEI SEBI, dan UIN Jakarta. Data dikumpulkan melalui penyebaran kuesioner secara digital. Data yang terkumpul kemudian dianalisis menggunakan analisis jalur jenis moderasi. Hasil penelitian ini menunjukan bahwa promosi digital berpengaruh terhadap perilaku konsumtifmahasiswa Perbankan Syariah dalam berbelanja online sebesar 20,5\%. Selain itu, religiusitas mampu menurunkan hubungan promosi digital dan perilaku konsumtif mahasiswa Perbankan Syariah dalam berbelanja online sebesar 16,2\%. Penelitian ini diharapkan dapat bermanfaat bagi konsumen muslim untuk mengontrol perilaku konsumtif mereka dengan cara meningkatkan religiusitasnya.
\end{abstract}

Kata kunci: Digital Promotion, Religiosity, Consumptive Behavior. 


\section{PENDAHULUAN \\ Latar belakang}

Dinamika dunia pemasaran semakin berkembang pesat di seluruh dunia. Penggunaan media internet berbasis online juga semakin diminati oleh masyarakat secara umum. Sampai saat ini terdapat lebih dari 300 perusahaan startup berstatus unicorn di seluruh dunia, dan empat di antaranya ada di Indonesia. Empat unicorn yang dimaksud adalah Gojek dengan valuasi sebesar 9,5 miliar dolar, Tokopedia (7 miliar dolar), Traveloka (4,1 miliar dolar), dan Bukalapak (1 miliar dolar) (Redaksi Tirto, 2019).

Salah satu alasan kuat mengapa perusahaan startup tersebut berkembang dengan sangat pesat adalah karena mereka menawarkan berbagai kemudahan kepada pelanggan, terutamadengan memaksimalkan pelayanan via online. Kemudahan ini tentu akan berdampak pada gaya hidup masyarakat yang semakin konsumtif dari waktu ke waktu. Sebuah hasil penelitian mengungkapkan bahwa persepsi, sikap, dan motivasi hedonis seseorang dapat berpengaruh secara signifikan terhadap keputusan pembelian melalui media online (Arthur, Oroh, \& Moniharapon, 2014).

Promosi melalui media online dan media sosial semakin intens akhir-akhir ini. Di sisi lain, menurut survei Badan Pusat Statistik perekonomian masyarakat Indonesia memang selalu mengalami peningkatan dari tahun ke tahun (Badan Pusat Statistik, 2019). Peningkatan status sosial dan ekonomi seseorang menjadi alasan yang kuat untukmengikuti gaya hidup modern yang cenderung konsumtif (Afriani, 2014).

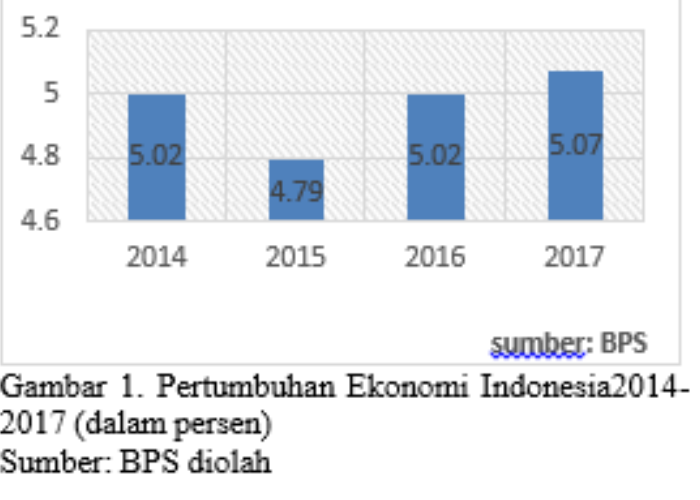

Pertumbuhan ekonomi masyarakat tentu berpotensi memunculkan perilaku konsumtif. Padahal Allah Swt melarang manusia untuk berbuat boros, dimana larangan ini termaktub dalam Alquran surat al-Isra'[17] ayat 26. Bahkan pada ayat berikutnya, Allah Swt mengatakan bahwa orang-orang yang berperilaku boros termasuk saudara setan, sedangkan setan sangat ingkar kepada (nikmat) Allah Swt.

Faktanya, berbagai promosi digital yang bervariasi bentuknya tersebut dapat membuat beberapa kelompok mahasiswa ini terpengaruh. Salah satu hasil penelitian menyimpulkan bahwa keberadaan online shop memang berpengaruh signifikan terhadap perilaku konsumtif mahasiswa (Saputra, Lubis, \& Wibowo, 2019). Ditambah lagi, tidak semua mahasiswa telah memiliki pekerjaan yang tetap dan masih mengandalkan uang saku dari orang tua. Sehingga apabila mahasiswa terjebak dalam perilaku konsumtif, maka ini justru akan membebani perekonomian kedua orang tua mereka. Tentu saja ini akan menjadi sebuah blunder yang sangat merugikan, baik secara personal maupun sosial.

Kajian yang dilakukan Godo Tjahjono (2014) menunjukkan bahwa religiusitas berpengaruh negatif terhadap keinginan untuk membeli suatu barang, apalagi jika barang tersebut mewah. Di sisi lain, penelitian yang dilakukan oleh Nasrullah berkesimpulan bahwa religiusitas dapat mengontrol pengaruh Islamic branding terhadap keputusan konsumen dalam membeli sesuatu (Nasrullah, 2015). Kedua hasil kajian tersebut semakin menguatkan asumsi peneliti bahwa religiusitas memang dapat memoderasi pengaruh promosi digital terhadap perilaku konsumtif mahasiswa dalam berbelanja online.

Promosi digital melalui media online dan media sosial semakin bervariasi bentuknya dan semakin marak dilakukan oleh para pelaku perdagangan. Intensitas promosi digital yang semakin meningkat dapat memberikan pengaruh yang cukup kuat terhadap perilaku konsumtif dalam berbelanja online, terutama bagi kalangan mahasiswa yang tidak pernah lepas dari penggunaan smartphone dan internet.

Penetrasi internet telah melampaui angka $50 \%$ dari total penduduk menurut survey APJII pada 2008. Dari total 262 juta jiwa, sebanyak 143,26 orang diperkirakan sudah menggunakan intenet dan sekitar $49 \%$ berasal dari kalangan milenial (CNN Indonesia, 2018). Ditambah lagi dengan pergaulan mahasiswa di daerah Jabodetabek yang dipengaruhi oleh gaya hidup metropolitan mendorong mahasiswa memiliki kecenderungan ingin selalu tampil beda, lebih stylish dan up-to-date di depan umum (A'yun,2019). 


\begin{abstract}
Keinginan tersebut dapat memicu pengeluaran uang berlebih untuk berbelanja. Padahal sebagai mahasiswa, khususnya mahasiswa Perbankan Syariah yang telah mempelajari ilmu ekonomi Islam, hendaknya mereka memiliki tingkat kesadaran yang lebih tinggi dalam membedakan antara kebutuhan dan kenginan. Namun fenomena yang terjadi menunjukan bahwa tidak sedikit mahasiswa syariah yang berperilaku konsumtif seiring dengan semakin berkembangnya promosi digital dalam berbagai bentuk.
\end{abstract}

\section{Tujuan peneitian}

Sejalan dengan pertanyaan penelitian yang telah dipaparkan sebelumnya, maka tujuan penelitian ini adalah:

1. Untuk mengekplorasi pengaruh promosi digital terhadap perilaku konsumtif mahasiswa Perbankan Syariah dalam berbelanja online.

2. Untuk mengeksplorasi pengaruh religiusitas terhadap hubungan promosi digital dan perilaku konsumtif mahasiswa Perbankan Syariah dalam berbelanja online.

\section{TINJAUAN PUSTAKA}

Promosi adalah komunikasi pemasaran yang digunakan untuk menginformasikan suatu penawaran kepada calon pelanggan sekaligus mempengaruhinya agar mereka menyelidiki penawaran itu lebih lanjut (McCarthy \& Perreault, 2012). Promosi dalam Islam yaitu segala sesuatu yang dilakukan oleh penjual atau produsen, baik terdiri dari perbuatan-perbuatan untuk memperkenalkan barang dagangan (komoditi) atau layanan-layanan yang mendorong dan menarik minat orang lain untuk memiliki dan membelinya, baik aktivitas itu sebelum akad jual beli atau sesudahnya (Bahri, 2013).

Promosi digital adalah bentuk komunikasi pemasaran yang dilakukan secara online untuk melibatkan pelanggan atau prospek, baik secara langsung maupun tidak langsung, sehingga mereka akan semakin mengenal suatu produk dan nantinya termotivasi untuk membeli produk tersebut (Kotler \& Keller, 2016, hlm. 582).

Promosi digital dapat dikategorikan menjadi tujuh bentuk, yaitu: 1 . Websites (situs web) 2. Search Ads (iklan di halaman pencarian) 3. Display Ads (iklan tampilan/iklan banner) 4 . E-mail (surat elektronik)5. Online Communities and Forums (komunitas dan forum online). 6. Blogs (Blog). 7. Social Networks (Jaringan Media Sosial) (Kotler \& Keller, 2016, hlm. 639644).
Religiusitas merupakan istilah yang memang diturunkan dari pengertian agama. Definisi umum yang disepakati banyak peneliti adalah bahwa religiusitas bersifat multidimensional (Fridayanti, 2015). Sungkar (2010) mendefinisikan religiusitas sebagai religiusitas adalah sejauh mana seseorang berkomitmen kepada agama beserta ajaran yang dianutnya, seperti sikap dan perilaku individu tersebut yang mencerminkan komitmen ini. Sejalan dengan definisi itu, religiusitas jiga didefinisikan sebagai tingkatan seseorang dalam memaknai keberagamaannya (Run, Butt, Fam, \& Jong, 2010). Dua definisi tersebut menitikberatkan makna religiusitas sebagai level atau kedalaman seseorang dalam beragama.

Mukhtar dan Butt (2012) menjelaskan bahwa religiusitas merupakan intensitas afiliasi seseorang terhadap agamanya. Sementara itu Muhammad Syukri Salleh (2012) mendefinisikan religiusitas sebagai keadaan keyakinan seseorang kepada Tuhan, yang ditandai oleh kesalehan dan semangat keagamaannya. Sehingga, dapat dikatakan bahwa semakin tinggi kesalehan dan semangat agamanya, maka semakin kuat keyakinannya kepada Tuhan, sekaligus akan semakin tinggi pula religiusitasnya.

Peneliti menemukan sebuah referensi yang dinilai dapat menjawab kegelisahan tersebut, yaitu hasil kajian Yasemin El-Menouar (2014). Dia mensintesakan berbagai pendapat para ahli untuk menyusun dimensi religiusitas yang dapat digunakan untuk mengukur aspek keberagamaan seorang muslim secara representatif.

Religiusitas muslim memiliki lima 1. Basic Religiosity (religiusitas dasar). 2. Central duties (kewajiban utama beragama). 3. Religious experience (pengalaman keagamaan) 4. Religious knowledge

(pengetahuan,keagamaan) 5. Orthopraxis (konsekuen si praktek keberagamaan) (El-Menouar, 2014).

Perilaku konsumtif merujuk kepada perilaku seseorang dalam membeli sesuatu secara berulang-ulang berdasarkan kesenangan semata, tanpa melihat kebutuhan dan rasionalitas (Shahjehan, 2012). Dengan kata lain, perilaku konsumtif adalah suatu perilaku seseorang dalam membeli sesuatu yang tidak lagi didasarkan pada pertimbangan yang rasional, melainkan karena adanya keinginan yang sudah mencapai taraf yang tidak rasional lagi. Perilaku konsumtif muncul karena 
beberapa sebab utama. Menurut Kotler dan Keller (2016), faktor-faktor tersebut secara umum meliputi faktor budaya, sosial, pribadi, dan psikologis. Perilaku konsumtif memiliki beberapa aspek khusus, dimana aspek ini sekaligus akan dijadikan landasan dalam penelitian ini. Aspek yang dimaksud meliputi:

1. Pembelian Impulsif (impulsive buying). Pembelian impulsif maksudnya adalah pembelian yang terjadi ketika konsumen mengalami desakan tiba-tiba, yang biasanya sangat kuat dan menetap untuk membeli sesuatu dengan segera. Pembelian impulsif memiliki beberapa karakteristik, yaitu:

a. Spontanitas

b. Kekuatan, kompulsif (bersifat mendorong/memaksa), intensitas

c. Kegairahan dan stimulasi

d. Ketidakpedulian akibat

2. Pemborosan. Perilaku konsumtif sebagai salah satu perilaku yang menghamburhamburkan banyak dana tanpa didasari adanya kebutuhan yang jelas.

3. Pembelian tidak rasional (non-rational buying). Suatu perilaku dimana konsumen membeli sesuatu semata-mata untuk mencari kesenangan (Miranda, 2017).

\section{METODE PENELITIAN}

Metode kuantitatif dipilih untuk melakukan penelitian skripsi ini, dimana metode kuantitatif ini akan menghasilkan data berupa angka-angka (Cresswell, 2012). Adapun jenis penelitian yang akan dilaksanakan merupakan penelitian asosiatif. Variabel dalam penelitian ini terdiri atas tiga jenis, yaitu variabel independen, dependen, serta variabel moderasi. Variabel Moderasi merupakan suatu variabel yang memiliki pengaruh pada hubungan antara variabel independen dan variabel dependen (Sekaran \& Bougie, 2016, hlm. 75).

Penelitian ini melibatkan sejumlah mahasiswa Perbankan Syariah dari tiga kampus yang berbeda di daerah Jabodetabek yaitu PNJ, STEI SEBI, dan UIN Jakarta. Dari populasi yang ada sejumlah 919 orang, peneliti menggunakan rumus slovin dalam menghitung jumlah sampelnya. Dengan rumus tersebut, didapatkan jumlah sampel sebanyak 279 orang. Peneliti menggunakan purposive sampling dalam memfilter responden agar lebih relevan dengan maksud dan tujuan dari penelitian ini. Kriteria yang digunakan untuk menentukan responden yaitu pernah berbelanja online minimal empat kali dalam waktu satu bulan dan berbelanja online dalam kurun waktu dua bulan terakhir (Sari, 2015).

Teknik pengumpulan data pada penelitian ini adalah melalui kuesioner dan dokumentasi. Data dikumpulkan sejak bulan Mei hingga Juli 2019.

\section{METODE PENELITIAN}

Metode kuantitatif dipilih untuk melakukan penelitian skripsi ini, dimana metode kuantitatif ini akan menghasilkan data berupa angka-angka (Cresswell, 2012). Adapun jenis penelitian yang akan dilaksanakan merupakan penelitian asosiatif. Variabel dalam penelitian ini terdiri atas tiga jenis, yaitu variabel independen, dependen, serta variabel moderasi. Variabel Moderasi merupakan suatu variabel yang memiliki pengaruh pada hubungan antara variabel independen dan variabel dependen (Sekaran \& Bougie, 2016, hlm. 75).

Penelitian ini melibatkan sejumlah mahasiswa Perbankan Syariah dari tiga kampus yang berbeda di daerah Jabodetabek yaitu PNJ, STEI SEBI, dan UIN Jakarta. Dari populasi yang ada sejumlah 919 orang, peneliti menggunakan rumus slovin dalam menghitung jumlah sampelnya. Dengan rumus tersebut, didapatkan jumlah sampel sebanyak 279 orang. Peneliti menggunakan purposive sampling dalam memfilter responden agar lebih relevan dengan maksud dan tujuan dari penelitian ini. Kriteria yang digunakan untuk menentukan responden yaitu pernah berbelanja online minimal empat kali dalam waktu satu bulan dan berbelanja online dalam kurun waktu dua bulan terakhir (Sari, 2015).

Teknik pengumpulan data pada penelitian ini adalah melalui kuesioner dan dokumentasi. Data dikumpulkan sejak bulan Mei hingga Juli 2019. Butir-butir item dalam kuesioner disusun berdasarkan aspek-aspek promosi digital, religiusitas, dan perilaku konsumtif sebagaimana yang tercantum dalam landasan teori.

Untuk menganalisis keterkaitan antar variabel yang ada, penelitian ini menggunakan analisis jalur. Analisis jalur merupakan pengembangan analisis regresi ganda yang menguraikan besaran pengaruh dari variabel bebas terhadap variabel terikat secara tidak langsung (Irianto, 2010, hlm. 283). Analisis jalur yang baik harus terbebas dari uji asumsi klasik. Uji asumsi klasik yang dilakukan yaitu uji autokorelasi dan uji heteroskedastisitas. Setelah dipastikan terbebas dari keduanya, selanjutnya dilakukan uji hipotesis. 
Uji hipotesis dilakukan dengan menggunakan analisis jalur (path analysis). Analisis jalur merupakan pengembangan analisis regresi ganda yang menguraikan besaran pengaruh dari variabel bebas terhadap variabel terikat secara tidak langsung (Irianto, 2010, hlm. 283). Dalam penelitian ini, analisis jalur yang digunakan adalah jenis moderasi, dimana terdapat variabel pihak ketiga yang dapat mempengaruhi hubungan antara variabel independen dan variabel dependen (Sekaran \& Bougie, 2016, hlm. $75)$.

Penjabaran tersebut secara matematis membentuk persamaan struktural yang menunjukkan hubungan yang dihipotesiskan. Adapun persamaan tersebut yaitu:

$$
\begin{aligned}
\mathrm{X}_{2} & =\rho_{2} \mathrm{X}_{1}+e_{1} \\
\mathrm{Y} & =\rho_{1} \mathrm{X}_{1}+\rho_{3} \mathrm{X}_{2}+e_{2}
\end{aligned}
$$

\section{HASIL PENELITIAN}

Untuk menjaga obyektifitas dan netralitas penelitian ini, peneliti menyebarkan kuesioner kepada 279 mahasiswa program studi Perbankan Syariah dari kampus PNJ, STEI SEBI, dan UIN Syarif Hidayatullah Jakarta. Potret responden dapat dilihat pada tabel berikut ini:

Tabel 1. Deskripsi Responden

\section{Hasil Uji Validitas dan Reliabilitas}

Suatu instrumen angket/kuesioner dikatakan valid jika $r_{\text {hitung }}>r_{\text {tabel. }}$. Sementara itu, reliabilitas angket terpenuhi jika nilai Cronbach Alpha > 0,60 (Arman, Arifin, Kamal, Putra, \& Pulansari, 2018, hlm. 241). Sebagai acuan, peneliti menghitung nilai $\mathrm{r}_{\text {tabel }}$ untuk 279 responden, dengan derajat kebebasan (degree of freedom $/ \mathrm{df}$ ) $=278$ dan taraf signifikansi/toleransi kesalahan sebesar 5\%.

Berdasarkan nilai $\mathrm{T}_{\text {tabel: } 0,05 ; 278}=1,968$, maka nilai rtabe 1:0,05;278 yang berlaku adalah:

$$
\begin{aligned}
& \boldsymbol{\nu}=\frac{1,968}{\sqrt{278+(1,968)^{2}}} \\
& \boldsymbol{\nu}=\frac{1,968}{\sqrt{278+3,874}} \\
& \boldsymbol{\nu}=\frac{1,968}{\sqrt{280,874}} \\
& \vartheta \approx 0,117 \mid
\end{aligned}
$$

Penentuan validitas item kuesioner dilakukan dengan cara membandingkan nilai $\mathrm{r}_{\text {hitung pada Corrected Item-Total Correlation }}$ dengan nilai $\mathrm{r}_{\text {tabel: }}: 0,05 ; 278=0,117$. Karena semuanya bernilai lebih besar dari 0,117 , maka keseluruhan item dapat dikatakan valid. Adapun reliabilitas item diputuskan dari nilai Cronbach Alpha pada kolom Cronbach Alpha if Item Deleted yang harus lebih besar dari 0,60. Karena masing-masing nilai Cronbach Alpha lebih besar dari 0,60, maka semua item reliabel. Hal ini dikuatkan dengan nilai Cronbach Alpha secara keseluruhan sebesar 0,727 yang juga lebih besar dari 0,60.

Untuk mendeteksi keberadaan

\begin{tabular}{|c|c|c|c|c|}
\hline \multicolumn{5}{|c|}{ Model Summaryb } \\
\hline $\begin{array}{c}\text { Mod } \\
\text { el }\end{array}$ & $\mathrm{R}$ & $\begin{array}{c}\mathrm{R} \\
\text { Square }\end{array}$ & \begin{tabular}{r|l} 
Adjuste & $\begin{array}{l}\text { Std. } \\
\mathrm{d} \\
\mathrm{Errror}\end{array}$ \\
$\mathrm{R}$ & $\mathrm{Er}$ \\
$\mathrm{t}$ & the \\
$\mathrm{S}$ & Estimate
\end{tabular} & $\begin{array}{l}\text { Durbin- } \\
\text { Watson }\end{array}$ \\
\hline 1 & .366 & 134 & 5.542 & 1.835 \\
\hline a. & $\begin{array}{l}\text { Predic } \\
\text { Prom }\end{array}$ & $\begin{array}{l}\text { ctors: } \\
\text { nosi }\end{array}$ & (Constant), & eligiusitas \\
\hline $\mathrm{De}$ & ende & ent $\mathrm{Va}$ & le: Perilaku Ko & sumtif \\
\hline
\end{tabular}
autokorelasi yaitu dengan melakukan uji statistic Durbin Watson(D-W). Analisis yang telah dilakukan menunjukkan hasil sebagai berikut:

Tabel 2. Uji Autokorelasi

Durbin-Watson sebesar 1,835. Dengan memperhatikan batas-batas nilai yang telah dikemukakan sebelumnya, maka dapat disimpulkan bahwa tidak terjadi autokorelasi.

Heteroskedastisitas dapat dilihat dari grafik scatterplot

Gambar 2. Uji Heteroskedastisitas

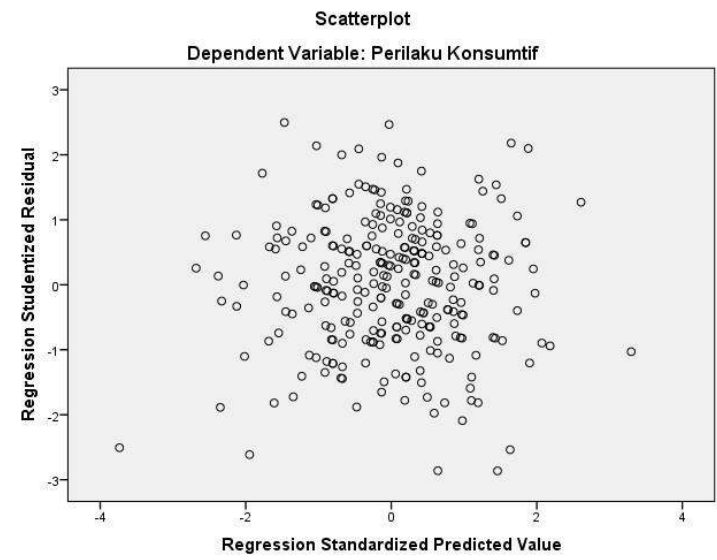


Berdasarkan grafik tersebut, terlihat bahwa tidak terbentuk pola tertentu. Titik-titik data juga menyebar di atas dan di bawah angka 0 pada sumbu Y. Dengan demikian dapat dikatakan bahwa dalam penelitian ini tidak terjadi heteroskedastisitas

\section{Hasil Uji Hipotesis}

Berdasarkan analisis yang telah dilakukan, didapatkan output SPSS untuk pengujian hipotesis pertama sebagai berikut:

Tabel 3. Uji Hipotesis 1

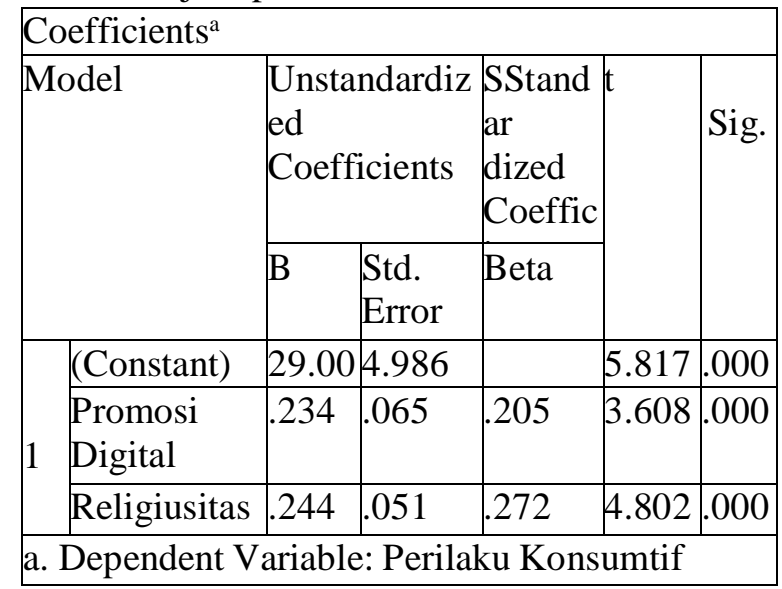

Sumber; Hasil Uji Statistik

Promosi digital sebesar 3,608 yang ternyata lebih besar daripada $T_{\text {tabel:0,05;277 sebesar }}$ 1,968, dengan signifikansi 0,000 maka Ho dapat ditolak. Dengan kata lain, perilaku konsumtif mahasiswa dipengaruhi oleh promosi digital. Adapun besarnya pengaruh dapat dilihat pada nilai Standardized Coefficients Beta, yaitu sebesar 0,205 dan signifikan pada 0,000 (lebih kecil dari 0,005). Artinya, promosi digital berpengaruh langsung terhadap perilaku konsumtif mahasiswa Perbankan Syariah dalam berbelanja online sebesar $20,5 \%$, dan sisanya $79,5 \%$ dipengaruhi faktor lain di luar model.

Sementara itu, analisis yang telah dilakukan untuk pengujian hipotesis kedua menghasilkan output sebagai berikut:

Tabel 4. Uji Hipotesis 2

\begin{tabular}{|c|c|c|c|c|c|}
\hline \multirow{3}{*}{\begin{tabular}{|l} 
Coefficients \\
Model
\end{tabular}} & & \multirow{3}{*}{$\mathrm{T}$} & \multirow{3}{*}{ Sig. } \\
\hline & \multicolumn{2}{|c|}{ Coefficients } & \multirow{2}{*}{\begin{tabular}{|l} 
ar \\
dized \\
Beta \\
\end{tabular}} & & \\
\hline & $\mathrm{B}$ & $\begin{array}{l}\text { Std. } \\
\text { Error }\end{array}$ & & & \\
\hline (Constant) & 68.515 & 4.219 & & 16.240 & .000 \\
\hline $\begin{array}{l}\text { Promosi } \\
\text { Dioital }\end{array}$ & 201 & .076 & 158 & 2.655 & .008 \\
\hline
\end{tabular}

Dari tabel tersebut diketahui bahwa nilai Standardized Coefficients Beta promosi digital terhadap religiusitas menunjukkan angka 0,158 dan signifikan pada 0,008 (lebih kecil dari 0,05). Nilai ini selanjutnya disebut sebagai $\rho_{2}$. Sementara itu pada tabel 4.11 sebelumnya, telah diputuskan pula bahwa promosi digital berpengaruh langsung terhadap perilaku konsumtif mahasiswa dengan koefisien jalur sebesar 0,205, dimana ini sebagai $\rho_{1}$ dan sekaligus sebagai pengaruh langsung. Pada tabel 4.3 sebelumnya juga tertera pengaruh religiusitas terhadap perilaku konsumtif mahasiswa ditunjukkan dengan nilai koefisien jalur sebesar 0,272, dimana ini sebagai $\rho_{3}$. Kesemuanya berada pada signifikansi 0,000 (berada di bawah 0,05), sehingga persyaratan menolak $\mathrm{H}_{0}$ telah terpenuhi.

Di sisi lain, koefisien jalur pengaruh tidak langsung promosi digital terhadap prestasi sebesar didapatkan dengan cara mengalikan koefisien jalur kedua $\left(\rho_{2}\right)$ dengan koefisien jalur ketiga $\left(\rho_{3}\right)$. Sehingga didapatkan pengaruh tidak langsung $=0,158 \times 0,272=0,043$.

Apabila dicermati berdasarkan perhitungan tersebut, maka terdapat selisih antara pengaruh langsung dan pengaruh tidak langsung sebesar 0,162 atau 16,2\%. Artinya, dapat dikatakan bahwa religiusitas mampu memoderasi hubungan promosi digital dan perilaku konsumtif mahasiswa Perbankan Syariah dalam berbelanja online sebesar 16,2\%.

\section{PEMBAHASAN HASIL}

\section{Pengaruh Promosi Digital terhadap Perilaku Konsumtif Mahasiswa Perbankan Syariah dalam Berbelanja Online}

Hasil penelitian ini menunjukkan bahwapromosi digital berpengaruh langsung terhadap perilaku konsumtif mahasiswa Program Studi Perbankan Syariah dalam berbelanja online sebesar $20,5 \%$, dan sisanya $79,5 \%$ dipengaruhi faktor lain di luar model. Hasil ini sejalan dengan kesimpulan penelitian dari Saputra dan timnya (2019) yang dipublikasikan dalam Jurnal Ilmu Komunikasi Volume 7 Nomor 1. Selain itu, hasil penelitian ini juga linier dengan penelitian dari Efendi bersama timnya (2018) yang dipublikasikan dalam Jurnal Pendidkan Ekonomi Volume 12 Nomor 1. Hasil penelitian ini juga mengkonfirmasi hasil penelitian dari Kusumaningrum bersama tim (2018) yang dipublikasikan dalam Jurnal Psikologi Volume 14, Nomor 1. Ketiga 
penelitian tersebut berkesimpulan bahwa promosi digital, dengan

berbagai bentuknya, berpengaruh signifikan terhadap perilaku konsumtif mahasiswa.

Pengaruh promosi digital terhadap perilaku konsumtif menunjukkan angka 20,5\%. Hal ini tidak mengherankan, karena promosi digital memiliki berbagai bentuk yang menarik dan sangat inovatif (Kotler \& Keller, 2016). Namun apabila dicermati kembali, perilaku konsumtif memang dipengaruhi oleh banyak faktor. Menurut Menurut Jisana (2014), perilaku pembelian konsumen dipengaruhi secara kuat oleh faktor budaya, sosial, personal, serta psikologis.

Selain itu, perlu diingat juga bahwa promosi digital adalah bagian dari konsep bauran pemasaran (marketing mix). Sebagai pengingat, bauran pemasaran itu sendiri terdiri atas produk (product), harga (price), promosi (promotion), dan penempatan (placement) (Furaiji, Łatuszyńska, \& Wawrzyniak, 2012). Dari sini dapat dipahami bahwa perilaku konsumtif tidak hanya dipengaruhi oleh promosi digital saja. Artinya, masih banyak faktor lain yang berpengaruh terhadap perilaku konsumtif seseorang.

\section{Religiusitas Memoderasi Hubungan Promosi Digital dan Perilaku Konsumtif Mahasiswa Perbankan Syariah dalam Berbelanja Online}

Hasil penelitian ini menunjukkan bahwa religiusitas mampu memoderasi hubungan promosi digital dan perilaku konsumtif mahasiswa Perbankan Syariah dalam berbelanja online sebesar $16,2 \%$.

Hasil penelitian ini searah dengan hasil penelitian dari Nasrullah (2015) yang dipublikasikan dalam Jurnal Hukum Islam (JHI) Volume 13 Nomor 2, yang berkesimpulan bahwa religiusitas dapat mengontrol pengaruh Islamic branding (sebagai bagian dari promosi) terhadap keputusan konsumen dalam membeli sesuatu. Selain itu, hasil penelitian ini juga sejalan dengan hasil penelitian Alam, Mohd, dan Hisham (2011) yang dipublikasikan dalam Journal of Islamic Marketing Volume 2 Nomor 1, yang berkesimpulan bahwa religiusitas seseorang merupakan faktor penting yang dapat mempengaruhi hubungan antara variabelvariabel relatif dan kontekstual terhadap perilaku pembelian konsumen Muslim di Malaysia.

$$
\text { Disadari atau tidak, Tingkat }
$$
keberagamaan seseorang akan membuat perilaku mereka lebih terarah, sehingga dapat mengontrol apa yang mereka lakukan. Hasil penelitian Ahmad bersama timnya (2015) menunjukkan bahwa pengetahuan tentang produk makanan dan kosmetik halal serta religiusitas seseorang dapat berpengaruh positif terhadap perilaku konsumen. Hal ini diperkuat dengan hasil penelitian disertasi Mahmood (2018) yang menyimpulkan bahwa religiusitas seseorang dapat mempengaruhi perilaku pembelian konsumen Muslim, khususnya terhadap makanan halal.

Sementara itu penelitian disertasi Tjahjono (2014) yang berfokus pada kelompok remaja Muslim di Jakarta mengungkap bahwa religiusitas berpengaruh negatif terhadap keinginan untuk membeli sebuah barang, apalagi jika barang tersebut termasuk dalam kategori barang mewah. Kesimpulan tersebut diperkuat dengan hasil penelitian Farrag dan Hassan (2015) yang menunjukkan bahwa religiusitas berpengaruh terhadap perilaku remaja Muslim di Mesir dalam hal fashion.

Penelitian yang dilakukan Mokhlis (2009) menunjukkan bahwa seseorang yang memiliki religiusitas tinggi cenderung lebih memperhatikan kepatutan harga dan kualitas produk saat mereka akan membeli sesuatu. Dengan demikian, ini akan mengurangi kebiasaan pembelian impulsif sekaligus mengontrol perilaku konsumtif mereka. Hal ini sejalan dengan hasil penelitian Yousaf dan Malik (2013) yang menyatakan bahwa seseorang dengan tingkat religiusitas yang tinggi cenderung mengabaikan aspek rekreasional yang hanya berpusat pada keinginan sesaat, tidak terpengaruh dengan adanya berbagai pilihan fashion yang ada, serta menghindari pembelian impulsif. Hal ini berbanding terbalik dengan mereka yang memiliki tingkat religiusitas yang rendah.

\section{KESIMPULAN}

Berdasarkan serangkaian analisis dan berbagai kajian yang telah dilakukan oleh peneliti, maka dapat disimpulkan bahwa:

1. Promosi digital berpengaruh langsung terhadap perilaku konsumtif mahasiswa Perbankan Syariah dalam berbelanja online sebesar 20,5\%, dan sisanya dipengaruhi oleh faktor lain di luar model analisis jalur dalam penelitian ini. Hal tersebut menunjukkan bahwa mahasiswa Perbankan Syariah masih banyak yang cukup terpengaruh dengan adanya berbagai bentuk promosi 
digital yang dibuat oleh para pelaku online marketing.

2. Religiusitas mampu memoderasi hubungan promosi digital dan perilaku konsumtif mahasiswa Perbankan Syariah dalam berbelanja online sebesar $16,2 \%$. Hal ini menunjukan bahwa religiusitas mempunyai pengaruh yang baik untuk menurunkan tingkat perilaku konsumtif SARAN mahasiswa dalam berbelanja online.

Peneliti merekomendasikan kepada para konsumen muslim, khususnya mahasiswa Perbankan Syariah untuk selalu berupaya meningkatkan religiusitas mereka agar dapat lebih mengontrol perilaku konsumtifnya dalam menyikapi perkembangan promosi digital yang semakin pesat. Di sisi lain, peneliti juga menyarankan para pelaku online marketing agar dapat mengembangkan usaha mereka secara lebih proporsional. Upaya yang dapat dioptimalkan misalnya dengan cara memaparkan deskripsi produk secara transparan, lengkap, dan jelas. Untuk menambah daya tarik promosi digitalnya di mata konsumen, setiap pelaku online marketing harus selalu berinovasi dan berkompetisi secara sehat di era global ini.

Peneliti menyadari bahwa hasil penelitian ini tentu mengandung banyak kekurangan, baik secara teknis maupun non-teknis. Oleh karena itu perlu diadakan penelitian lebih lanjut dengan cakupan sampel yang lebih luas, jumlah responden yang lebih banyak, atau dengan mengikut sertakan lebih banyak variabel lain dalam model analisisnya. Karena itulah, kesimpulan dari penelitian ini hanya akan dapat digeneralisasikan pada obyek yang memiliki keadaan yang identik dengan setting penelitian ini.

\section{DAFTAR PUSTAKA}

Afriani, R. (2014). Hubungan Status Sosial Ekonomi Dan Perilaku Konsumtif Pada Mahasiswi (Studi kasus: Mahasiswi FISIP UIN Syarif Hidayatullah Jakarta). UIN Syarif Hidayatullah, Jakarta.

Ahmad, A. N., Rahman, A. A., \& Rahman, S. A. (2015). Assessing Knowledge and Religiosity on Consumer Behavior towards Halal. Food and Cosmetic Products. International Journal of Social Science and Humanity, 5(1), 10-14. https://doi.org/10.7763/IJSSH.2015.V5.41 3

Alam, S. S., Mohd, R., \& Hisham, B. (2011). Is religiosity an important determinant on Muslim consumer behaviour in Malaysia?
Journal of Islamic Marketing, 2(1), 83-96. https://doi.org/10.1108/17590831111115 268

Anwar, A. (2009). Statistika Untuk Penelitian Pendidikan dan Aplikasinya dengan SPSS dan Excel. Kediri: IAIT Press.

Arman, R. F., Arifin, F. A. M., Kamal, M. F., Putra, I. K. K., \& Pulansari, F. (2018). Desain Produk Banley (Barcode Scanner Trolley) Terhadap Fleksibilitas Layanan Pembelian Produk. Prosiding SEMATEKSOS 3, (5), 236-244.

Arthur, A., Oroh, S. G., \& Moniharapon, S. (2014). Persepsi, Sikap, Dan Motivasi Hedonis Terhadap Keputusan Pembelian Produk Fashion Secara Online. Jurnal EMBA, 2(1), 561-570.

A'yun, A. Q. (2019). Gaya Hidup Mahasiswa Pengguuna Online Shop (Studi pada Mahasiswa PGSD UNUSA) (Undergraduate Thesis). UIN Sunan Ampel, Surabaya.

Badan Pusat Statistik. (2019). Upah Pegawai/Karyawan/Buruh. Diambil 17 Februari 2019, dari Badan Pusat Statistik Online website https://www.bps.go.id/subject/19/upah-buruh.html\#subjekViewTab3

Bahri, S. (2013). Hukum Promosi Produk Dalam Perspektif Hukum Islam. Episteme, 8(1), 135-154.

CNN Indonesia. (2018, April 19). Alasangenerasi milenial lebih konsumtif. Diambil 20 Maret 2019, dari CNN Indonesia website: https://m.cnnindonesia.com/gayahidup/20180418215055-28

291845/alasan- generasi-milenial-lebih konsumtif

Cresswell, J. W. (2012). Research Design: Pendekatan Kualitatif, Kuantitatif dan Mixed. Yogyakarta: Pustaka Pelajar.

Efendi, M. R., Wahyuni, S., \& Zulianto,M. (2018). Pengaruh Facebook Sebagai Social Media Marketing Terhadap Perilaku Konsumtif Mahasiswa (Studi Kasus Pada Mahasiswa Pendidikan Ekonomi FKIP Universitas Jember). Jurnal Pendidikan Ekonomi, 12(1), 82-87.

El-Menouar, Y. (2014). The Five Dimensions of Muslim Religiosity. Results of an Empirical Study. MDA Journal (Methods, Data, Analyses), 8(1), 53-78.

Farrag, D. A., \& Hassan, M. (2015). The influence of religiosity on Egyptian 
Muslim youths' attitude towards fashion. Journal of Islamic Marketing, 6(1), 95-108. https://doi.org/10.1108/JIMA-04-20140030

Fridayanti. (2015). Religiusitas, Spiritualitas Dalam Kajian Psikologi Dan Urgensi Perumusan Religiusitas Islam. Psympatic, 2(2), 199-208.

Furaiji, F., Łatuszyńska, M., \& Wawrzyniak, A. (2012). An Empirical Study of the Factors Influencing Consumer Behaviour in the Electric Appliances Market. Contemporary Economics, 6(3), 76-86. https://doi.org/10.5709/ce.1897-9254.52

Ghozali, I. (2013). Aplikasi Analisis Multivariate dangan Program SPSS. Semarang: Undip Press.

Hasan, D. B. N. (2014). Syariah Marketing. Dinar: Jurnal Ekonomi dan Keuangan Islam, 1(2), 1-17.

Irianto, A. (2010). Statistik: Konsep Dasar, Aplikasi dan Pengembangannya. Jakarta: Kencana.

Jisana, T. K. (2014). Consumer Behaviour Model: An Overview. Sai Om Journal of Commerce \& Management, 1(5), 34-43.

Kotler, P., \& Keller, K. lane. (2016). Marketing Management (15 ed.). London: Pearson.

Kusumaningrum, A., Wicaksono, B., \& Saniatuzzulfa, R. (2018). Hubungan Electronic Word of Mouth dan Hedonic Shopping Motivation dengan Perilaku Konsumtif Produk Make Up pada Mahasiswi. Jurnal Psikologi, 14(1), 50-59.

Maheshwari, V., Sinnott, K., \& Morris, B. (2018). Digital Marketing and the Young Consumer. Dalam Young Consumer Behaviour: a Research Companion (hlm. 188-207). New York: Routledge.

Mahmood, S. M. J. (2018). Religiosity Among Muslim Consumers And Its Impact On Consumer Buying Behaviour Towards Food Products In Delhi And Ncr (Dissertation). Aligarh Muslim University, India.

McCarthy, E. J., \& Perreault, W. D. (2012). Basic Marketing: A Global-Managerial Approach (14th ed.). Homewood: McGraw Hill.

Miranda, S. (2017). Pengaruh Instagram Sebagai Media Online Shopping Fashion Terhadap Perilaku Konsumtif Mahasiswi Fakultas Ilmu Sosial Dan Ilmu Politik Universitas Riau. JOM FISIP, 4(1), 1-15.
Mokhlis, S. (2009). Relevancy and Measurement of Religiosity in Consumer Behavior Research. International Business Research, 2(3). https://doi.org/10.5539/ibr.v2n3p75

Mukhtar, A., \& Butt, M. M. (2012). Intention to Choose Halal Products: the Role of Religiosity. Journal of Islamic Marketing, 3(2), 108-120.

Nasrullah, M. (2015). Islamic Branding, Religiusitas Dan Keputusan Konsumen Terhadap Produk. Jurnal Hukum Islam (JHI), 13(2), 79-87.

Redaksi Tirto. (2019, Februari 19). Mengenal Unicorn, Decacorn, dan Hectocorn dalam Startup. Diambil 16 Februari 2019, dari Tirto Online website: https://tirto.id/mengenalunicorn-decacorn-dan-hectocorn-dalamstartup- dhk9

Run, E. D., Butt, M., Fam, K., \& Jong, T. (2010). Attitudes towards Offensive Advertising: Malaysian Muslims. Journal of Islamic Marketing, 1 (1 25-36.

Salleh, M. S. (2012). Religiosity in Development: A Theoretical Construct of an Islamic-Based Development. International Journal of Humanities and Social Science, 2(14), 266.

Saputra, A. R., Lubis, H., \& Wibowo, S. E. (2019). Pengaruh Terpaan Online Shop Di Instagram Terhadap Perilaku Konsumtif Mahasiswa (Studi Pada Mahasiswa Prodi Ilmu Komunikasi Fisip Unmul). Jurnal Ilmu Komunikasi, 7(1), 142-153.

Sari, C. A. (2015). Perilaku Berbelanja Online Di Kalangan Mahasiswi Antropologi Universitas AntroUnairDotNet, 4(2), 205-216.

Sekaran, U., \& Bougie, R. (2016). Research Methods for Business: A Skill (7th ed.). New Jersey: Wiley.

Shahjehan, A. (2012). The Effect of Personality on Impulsive Buying Behaviors. ournalof Business Management, 6(6), 2187-2194.

Sungkar, I. (2010, April). Consumer Awareness: Thoughts and Trends across the Globe. The Halal Journal, (33), 22-24.

Tjahjono, G. (2014). Religiosity and the Intention to Buy Luxury Goods Among Young Indonesian Muslims in Jakarta (Dissertation). University of Western Sydney, Australia, Sydney. 
Tukamushaba, E. K., \& Musinguzi, D. (2018). Faith, Religion and Young Consumer Behaviour. Dalam Young Consumer Behaviour: a Research Companion (hlm. 334-346). New York: Routledge.

Wanita, N. (2016). Bauran Promosi (Promotion Mix) Konvensional Dalam Perspektif Etika Bisnis Islam. Bilancia, 10(1), 27-50.
Yousaf, S., \& Shaukat Malik, M. (2013). Evaluating the Influences of Religiosity and Product Involvement Level on the Consumers. Journal of Islamic Marketing, 4(2), 163-186. https://doi.org/10.1108/17590831311329 29 
